\title{
Intensive Probing of a Clear Air Convective Field by Radar and Instrumented Drone Aircraft
}

\author{
J. R. RowLAND \\ Applied Plyysics Laboratory, The Jolns Mopkins University, Silver Spring, Md. 20910
}

(Manuscript received 24 April 1972, in revised form 27 September 1972)

\begin{abstract}
An instrumented drone aircraft was used in conjunction with ultrasensitive radar to study the development of a convective field in the clear air. Radar data are presented which show an initial constant growth rate in the height of the convective field of $3.8 \mathrm{~m} \mathrm{~min}^{-1}$, followed by a short period marked by condensation and rapid growth at a rate in excess of $6.1 \mathrm{~m} \mathrm{~min}^{-1}$.

Drone aircraft soundings show general features of a convective field including progressive lifting of the inversion at the top of the convection and a cooling of the air at the top of the field. Calculations of vertical heat flux as a function of time and altitude during the early stages of convection show a linear decrease in heat flux with altitude to near the top of the convective field and a negative heat flux at the top.

Evidence is presented which supports previous observations that convective cells overshoot their neutral buoyancy level into a region where they are cool and moist compared to their surroundings. Furthermore, only that portion of the convective cell that has overshot its neutral buoyancy level is generally visible to the radar.
\end{abstract}

\section{Introduction}

Convective cells and fields of convective cells have been studied with instrumented aircraft by many researchers including Grant (1965), James (1953), Warner and Telford (1963,1967), and Woodward (1958). It is extremely difficult, however, to obtain a complete picture of the convective field in the clear air from point measurements made with an aircraft.

Characteristics of the convective field such as vertical extent, field uniformity, cell alignment, cell size and spacing, and the location of perturbing influences such as the sea breeze are difficult to obtain from aircraft measurements alone. In many studies, cumulus clouds have served as indicators of the top of the convective field. Cumulus clouds are not generally present during the earliest stages of convection. Furthermore, the effects of cloud formation upon the convective process in the clear air are not completely understood.

The development of convective cells and fields of convective cells in the optically clear atmosphere has been studied extensively with the high-power, highresolution Wallops Island radars as indicated by Hardy and Katz (1969), Hardy and Ottersten (1969), Konrad (1970a), and Konrad and Kropfli (1968). The radars allow individual convective cells to be seen by virtue of the small-scale, refractive index gradients caused by mixing of the air within the convective cell with the surrounding air which has a different temperature and humidity. The mixing takes place at the boundary of the cell and the environment, enabling the shell of the convective cell to be seen by the radar.
Radar provides an overall picture of the convective field through most of its life cycle without relying upon clouds as indicators. Characteristics such as cell alignment, size and spacing as a function of time and altitude, uniformity and vertical extent of the convective field, and the location of perturbing influences such as the sea breeze may be determined directly from pictures taken with the radar. Radar observations, however, must be supplemented by point meteorological measurements in order to relate the radar measurements to actual meteorological processes. It is desirable to have measurements of the profiles of temperature and humidity at short time intervals over periods of several hours in order to study rapidly growing convective fields such as noted in Konrad (1970b).

Recently, Katz (1970) and Konrad (1970b) have described experiments in which convective cells and fields of convective cells were studied with simultaneous instrumented aircraft and radar observations in the clear air.

A small instrumented drone aircraft has been developed by Konrad et al. (1970) as a low cost platform from which meteorological measurements can be made. The drone is capable of making repeated soundings over a fixed ground location from the surface to an altitude in excess of $1200 \mathrm{~m}$. This paper contains a description of the results of an experiment conducted on 17 July 1970 near Wallops Island, Va., in which the drone and radars were used to study the development of a clear air convective field. 


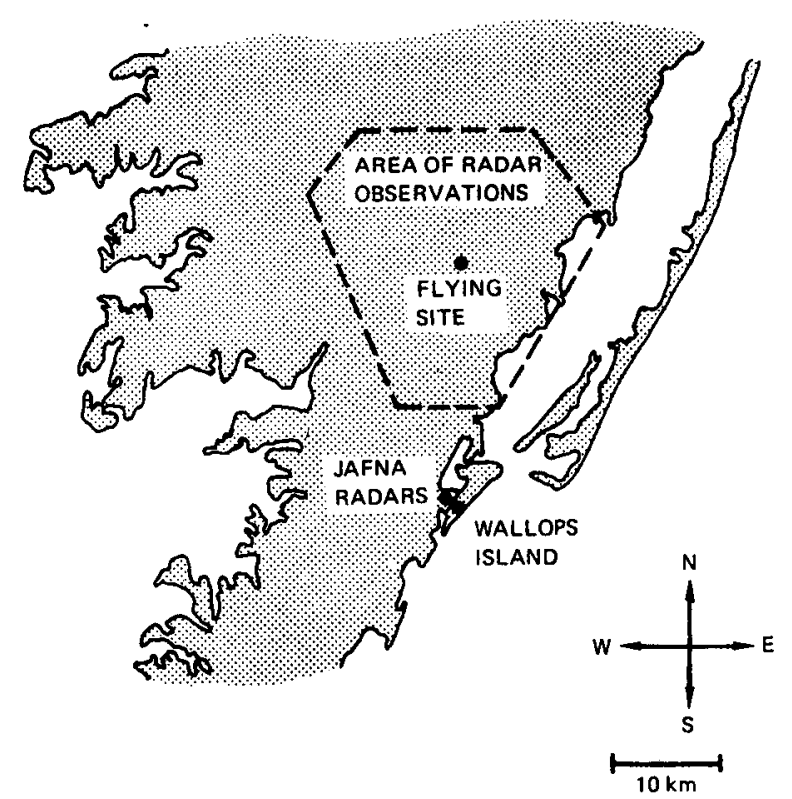

IiIg. 1. Map indicating the locations of the flying field, radars, radiosonde releases, and the area of radar observation.

\section{Experiment description}

\section{a. Drone aircraft}

The drone as used in the 17 July 1970 test had a takeoff weight of $5.2 \mathrm{~kg}$, wingspan $2.5 \mathrm{~m}$, maximum rate of climb $4.5 \mathrm{~m} \mathrm{sec}^{-1}$, and a cruising speed of 10.3 $\mathrm{m} \mathrm{sec}^{-1}$ in a power-off glide. The aircraft was instrumented to take continuous measurements of temperature with a thermistor (VECO 32A402C), pressure altitude with a potentiometric pressure sensor (Bourns 2004261011), relative humidity with a carbon film sensor (Viz Premium Hygristor), and aircraft vertical velocity and airspeed with special heated thermistor sensors described in Rowland (1971a). All sensors had a frequency response better than $1 \mathrm{~Hz}$. The data were telemetered to the ground and recorded on magnetic

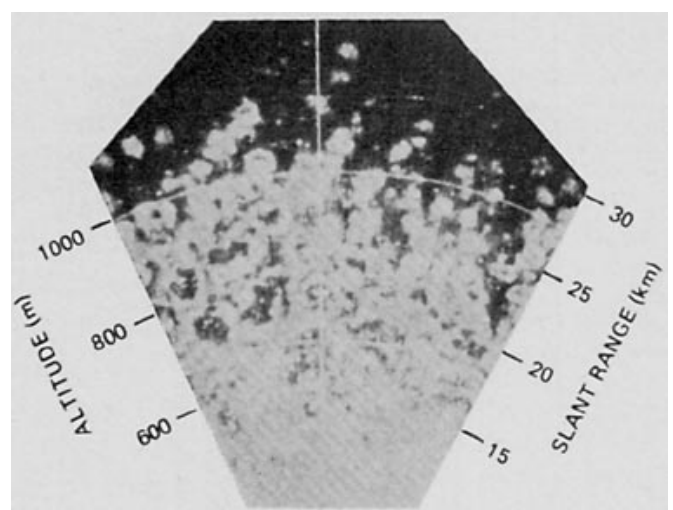

FIG. 2. Photograph of PPI scope taken at 1022 EST 17 July 1970 , showing the characteristic doughnut-like echoes of convection in a horizontal plane. tape. Approximately 4 hr of data recorded on magnetic tape were later processed on an analog computer. All data were played through a $1-\mathrm{Hz}$ low-pass filter before processing on the computer to eliminate errors in the computations duc to incorrectly matched sensor responses.

In the 17 July test, the drone was used to make a series of soundings beginning at 0652 and ending at 1317 (all times EST). Sixteen complete soundings were made covering the altitude range from the surface to at least $1 \mathrm{~km}$. A good statistical sample of the meteorological parameters over the flying site was obtained with the drone since it was actually airborne and used to take data in excess of one-third the time period of the experiment.

\section{b. Radar}

Radar pictures were taken with the S-band $(10 \mathrm{~cm})$ Joint Air Force-NASA (JAFNA) radar. The radar which is described by Hardy and Katz (1969), has a $0.5^{\circ}$ beamwidth and a peak transmitted power of $3 \mathrm{MW}$. Pictures of Range Height Indicator (RHI) displays were taken over the flying site and along a $20^{\circ}$ azimuth either side of the site. Plan Position Indicator (PPI) display pictures were taken at stepped elevation angles in the sector in which the drone was flying. A complete series of pictures was taken approximately every 30 min between 0553 and 1343 .

\section{c. Flying site}

The site from which the drone was flown is located $23.2 \mathrm{~km}$ north of the radar and $2.7 \mathrm{~km}$ inland from the coast. The land is flat with an elevation a few meters above sea level. A large portion of the land is under cultivation while the majority of the remainder is wooded. The actual field from which the drone was flown consisted of mowed grass over a soil of sandy loam.

\section{d. Supplementary data}

Radiosondes released from Wallops Island at 0615 and 1000 on 17 July have been helpful in interpreting the data obtained with the drone. Fig. 1 shows the relative locations of the radar, the flying field, and the location of the radiosonde releases at Wallops Island.

\section{Results}

\section{a. Growth of the convective field with time}

Fig. 2 is a picture of a PPI display taken at 1022 and shows in a horizontal section the characteristic doughnut-like echoes of individual convective cells. An outline of the area included in the picture is enclosed by a dashed line in Fig. 1. Fig. 3 was prepared from the PPI and RHI pictures and shows the height of the top of the convective field as a function of time. Prior 
to 0635 , no radar returns from convection were detected. From 0635 until the end of observations, the top of the convection layer was present in all pictures taken with the S-band radar.

It should be noted that during the period of radar and aircraft observations the winds throughout the convection layer were light and from the NNE. The indication is that air passing over the flying site had been over land for a considerable time. This fact was probably responsible for a good spatial uniformity in the convective field noted on this day. In contrast, it is often noted that when the winds are from the east off the ocean at this time of year, the height of the convective field is proportional to the distance inland from the shore line.

Fig. 3 shows a linear growth rate for the convective field height of $\sim 3.8 \mathrm{~m} \mathrm{~min}^{-1}$ between 0635 and 1020 . Such a growth rate is only slightly lower than those reported by Konrad (1970b) who observed typical growth rates of $4.5-6 \mathrm{~m} \mathrm{~min}^{-1}$. Also, a linear extrapolation back to a zero convective field height occurs at 0515 ; sunrise occurs at 0453 .

Between 1020 and 1135, the top of the convective field rose from 1150 to $1600 \mathrm{~m}$ representing an average growth rate of $6.1 \mathrm{~m} \mathrm{~min}^{-1}$. Since no pictures were taken during this time period the actual growth rate may be even greater. Although no drone aircraft flights extended above $1100 \mathrm{~m}$ on this day, the data from a radiosonde released at 1000 at Wallops Island were available. Plots of mixing ratio and saturation mixing ratio vs altitude prepared from the radiosonde data are shown in Fig. 4 and indicate a possibility of condensation in the vicinity of $1370 \mathrm{~m}$. The radiosonde data also indicates that clouds forming at $1370 \mathrm{~m}$ might evaporate as they ascended past this level into relatively dry air. This conclusion is supported by

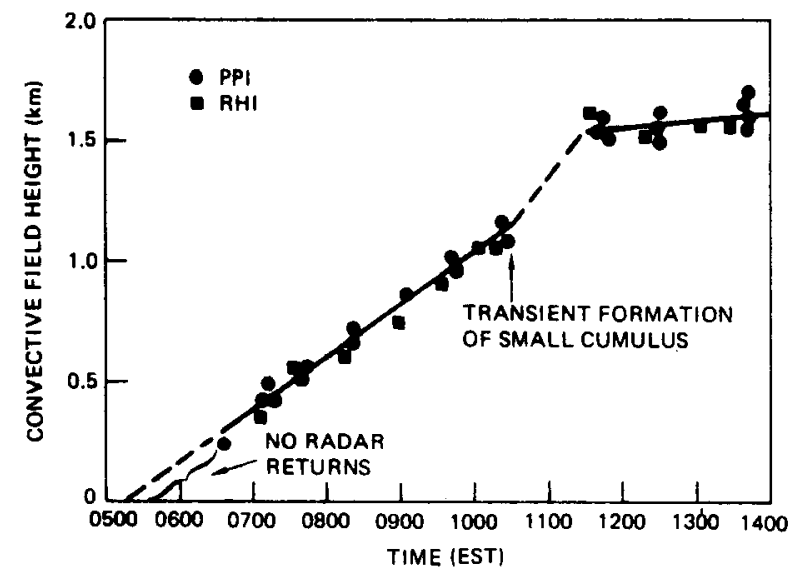

FIG. 3. Convective field height as a function of time from the radar. Note the linear growth rate of the convective field until 1030 , the rapid increase in the height of the convective field after 1030 due to cloud formation, and the limiting of the convective field height to below $1680 \mathrm{~m}$ due to a strong inversion. Note also the extrapolation back to a zero convective field height occurs at 0515 with local sunrise at 0453 .

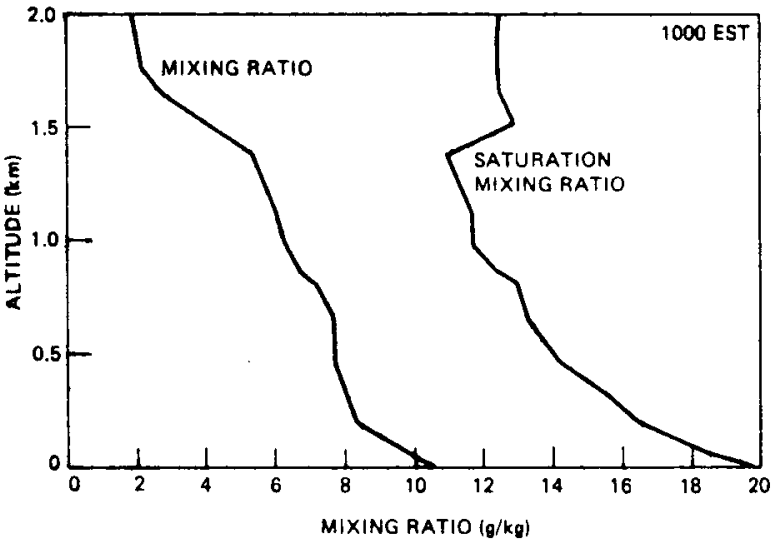

FIG. 4. Mixing ratio and saturation mixing ratio from the 1000 EST radiosonde. Note a region of possible condensation in the vicinity of $1370 \mathrm{~m}$ for a moist parcel rising from the ground.

observations made in the field at 1030. At this time, it was noted that small, thin cumulus began forming and upon forming immediately dissipated. The whole process of formation and dissipation took only a few minutes. The evidence, therefore, points to condensation with the accompanying release of latent heat as the most probable cause of the short period of rapid growth.

Significant growth in the height of the convective field ended at 1130 . Plots of virtual potential temperature vs altitude prepared from data obtained with the 0615 and 1000 radiosondes (Fig. 5), show the air above $1450 \mathrm{~m}$ to be quite stable. This region of great stability was probably responsible for limiting the height of the convective field.

\section{b. Aircraft soundings}

The information recorded on magnetic tape from the telemetered drone data were processed on an analog

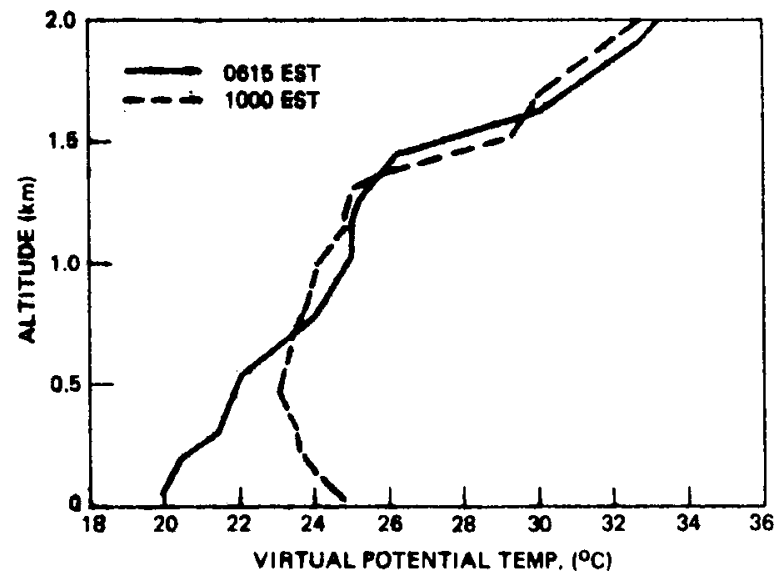

Fig. 5. Virtual potential temperature from the 0615 and 1000 radiosondes. Note the strong inversion at $1450 \mathrm{~m}$ that was responsible for eventually limiting the height of the convective field. 


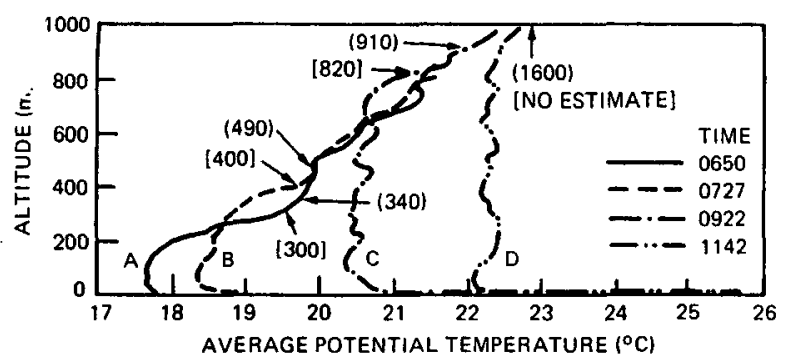

FIG. 6. Representative soundings of potential temperature taken with the drone aircraft. Note the stability of the air above the convection, the cooling effect of the convection at the top of the convective field, the nearly adiabatic lapse rate of the air within the convection layer, the thin superadiabatic layer near the ground, and the progressive heating of the air within the convection layer. The terms in the brackets indicate height of the convective field as estimated from the sounding, while those in parentheses indicate height of the convective field as estimated from the radar at the time sounding was made.

computer to produce mixing ratio, potential temperature, virtual temperature, and virtual potential temperature. In addition, an attempt has been made to obtain rough measurements of the vertical velocities of air within convective cells in a manner similar to that used by Jones (1954) in a study of vertical velocities in thunderstorms. The exact method, described in Rowland (1971b), uses the aircraft airspeed and vertical velocity data as inputs to an analog circuit which produces an output that is a measure of vertical air velocities uncontaminated by the first-order effects of aircraft motions. When obtaining data on vertical air velocities the engine of the drone is shut down, and the drone is flown as a glider with only a minimum of rudder control being applied. The descent rate of the drone with its engine off in still air under the condition of neutral elevator is less than $1.7 \mathrm{~m} \mathrm{sec}^{-1}$ with an airspeed of $10.3 \mathrm{~m} \mathrm{sec}^{-1}$. These characteristics along with its small size make the drone a very sensitive indicator of vertical air motions. In the 17 July 1970 test, however, the drone experienced rather severe phugoid motion with a period of roughly $5 \mathrm{sec}$. Only a portion of the data was considered of suitable quality for analysis of vertical air velocities. Later tests have incorporated aerodynamic changes that have reduced the phugoid and has enabled real-time analysis of vertical air velocities in the field.

The processed drone data from 16 soundings were used to make machine plots of average potential temperature vs altitude. Fig. 6 shows several representative soundings. Sounding $\mathrm{A}$ is the first and was made after the convective field had begun to grow. Three regions are recognizable on all soundings passing through the top of the convective field: the thin superadiabatic layer next to the ground, the region of nearly adiabatic lapse rate extending from the superadiabatic layer to the top of the convective field, and the stable air above the top of the convection. By comparing the regions of soundings $\mathrm{A}$ and $\mathrm{B}$ between 250 and $400 \mathrm{~m}$ and soundings $B$ and $C$ between 650 and $800 \mathrm{~m}$, it can be seen that the convection has a cooling effect at the top of the convective field. The decrease in average temperature at a given altitude near the top of the convective field is caused by the collective effect of many cells rising past their neutral buoyancy level, due to their momentum, to a level where they are cooler than their surroundings and have a negative buoyancy. The progressive warming of the convective layer, after the initial cooling period at the top of the field, may be noted by comparing soundings A-D. Sounding D did not extend to the top of the convective field. As indicated in Fig. 6, the height of the convective field as determined with the radar agrees to within $90 \mathrm{~m}$ of the height estimated from the aircraft soundings.

Fig. 7 is a representative sounding of mixing ratio and corresponds to sounding $\mathrm{C}$ of Fig. 6 . The important features to notice are the well-mixed region with a constant mixing ratio and an adiabatic lapse rate, the very moist region near the surface presumedly produced by evaporation from the ground and corresponding to the superadiabatic layer, and the region of relatively dry air above the convection. Under these circumstances, it would be expected that rising convective cells would generally have a moisture excess over their surroundings throughout the entire depth of the convective field.

In Fig. 8 virtual potential temperature, mixing ratio,

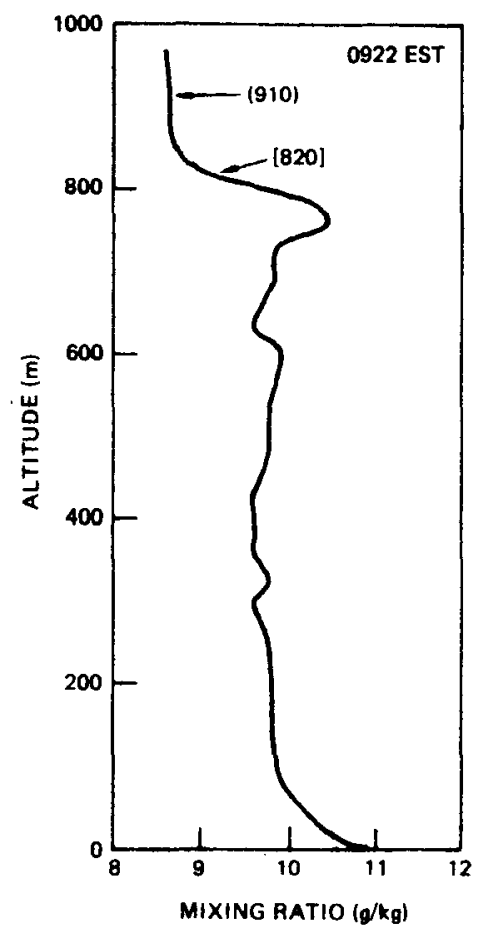

Frg. 7. Representative sounding of mixing ratio corresponding to potential temperature sounding $\mathrm{C}$ of Fig. 6 . Note the dry region above the convection, the constant mixing ratio within the convection layer and the moist region near the ground corresponding to the superadiabatic layer. See legend to Fig. 6 . 
and altitude are shown for four selected segments from sounding $\mathrm{C}$. The first region extends from approximately $60-190 \mathrm{~m}$ and shows the relatively large positive excesses in virtual potential temperature and mixing ratio characteristic of elements breaking away from the superadiabatic layer. The second region extends from $215-430 \mathrm{~m}$ and illustrates the reduced positive excess of temperature and mixing ratio at intermediate altitudes. In each of these segments the excellent positive correlation in the detail of mixing ratio and virtual potential temperature is evident. In the region between 580 and $730 \mathrm{~m}$, individual convective elements appear nearly indistinguishable from their surroundings. The correlation in the detail of mixing ratio and virtual potential temperature is less pronounced. In the region between 840 and $915 \mathrm{~m}$, however, the rising convective cells have penetrated into the dry stable region which
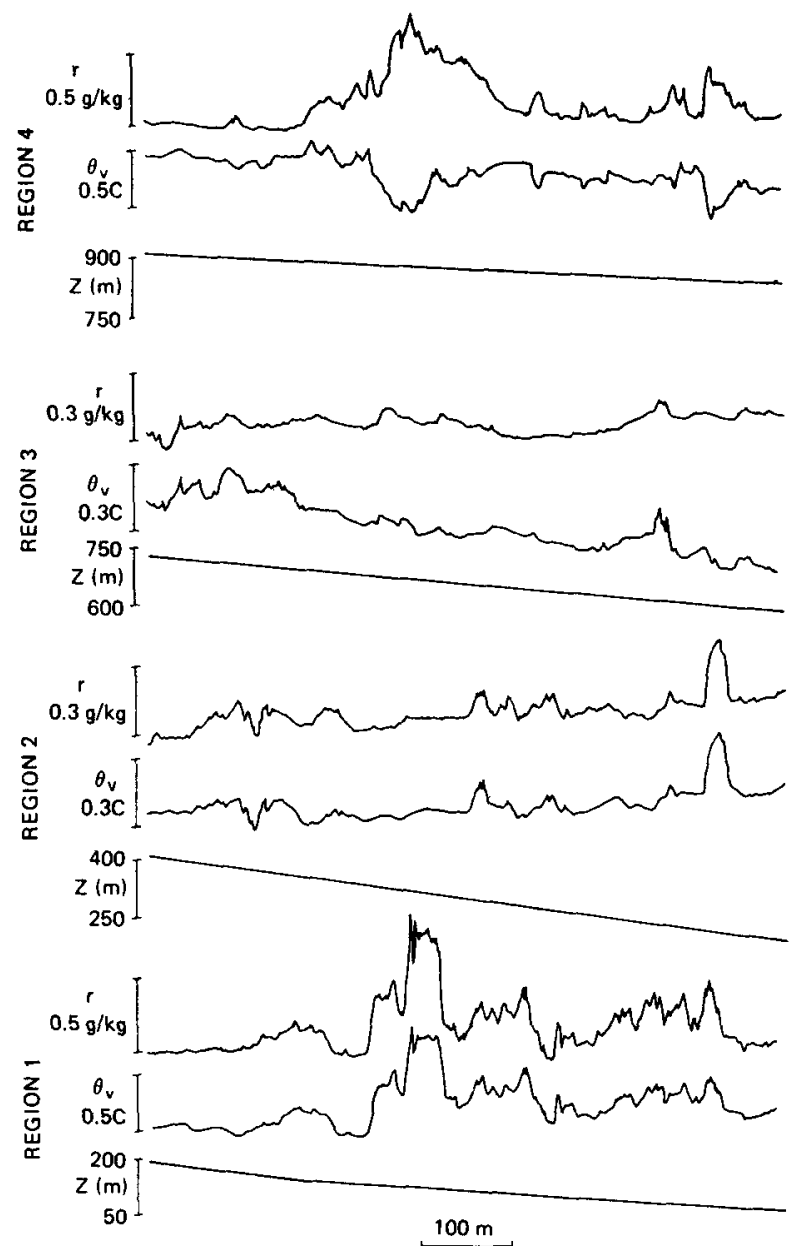

FIG. 8. Detailed records of mixing ratio $(r)$, virtual potential temperature $\left(\theta_{v}\right)$, and altitude $(z)$ for selected altitude ranges of sounding $\mathrm{C}$ in Fig. 6 . Note that in the first two regions rising convective cells may be recognized by their positive temperature and humidity excesses. In the third interval, cells are generally unrecognizable from their environment. At the top of the convective field cells overshoot their neutral buoyancy level, into a drier region, and appear cold and moist when compared with their environment.

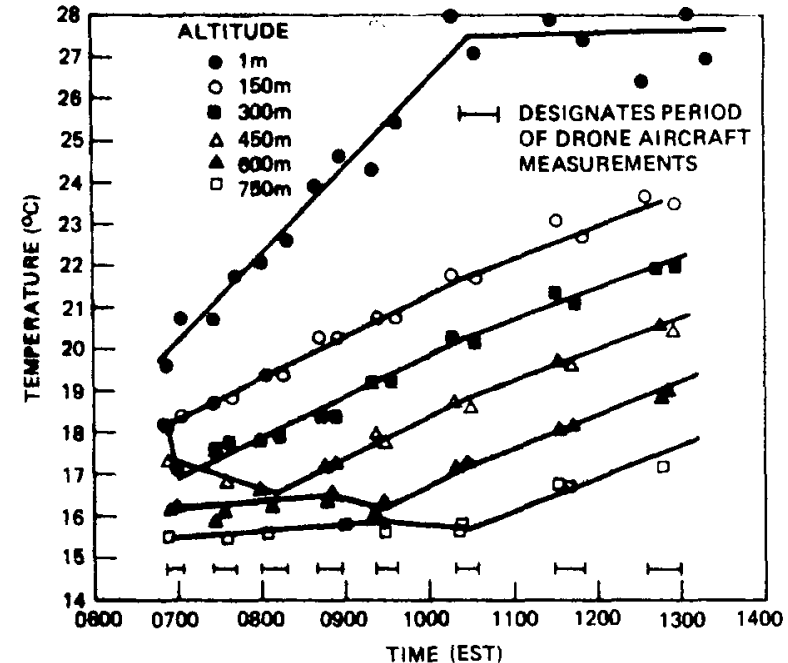

Fig. 9. Mean temperature as a function of time and altitude ohtained from the drone aircraft. Note the initial decrease in temperature at each altitude due to the overshoot of the convective cells past their neutral buoyancy level. After this initial decrease note the linear increase in temperature with time.

extends above the convective field, and the cells appear to have a rather large moisture excess over their environment, are cooler than their environment, and have a negative buoyancy. The excellent negative correlation in the detail of the temperature and humidity traces in this region is striking.

The behavior of the temperature and humidity traces observed in the sounding is to be expected considering the profiles of potential temperature and mixing ratio given in Figs. 6 and 7, respectively. Buoyant elements originating in the superadiabatic layer would initially exhibit large positive temperature and mixing ratio excesses over their environment. As the elements rose through an environment with a nearly neutral lapse rate in potential temperature and mixing ratio, entraining air as they rose, they would take on the characteristics of their environment while continuously losing buoyancy.

The presence of convective cells which are cool and moist with respect to their surroundings through a significant portion of the convection layer has been noted by Konrad (1970a, b), Katz (1970), Grant (1965). and James (1953). Grant (1965) also noted that in many cases cells have a negative buoyancy with respect to their surroundings. The observed characteristics of the temperature and humidity soundings are consistent with the models of Konrad (1970a, b) and Grant (1965).

During the course of this experiment and many others conducted with the drone and radars over a four-year period, one characteristic of the convective field has always been noted: the lowest altitude from which there were clear air radar returns from convection in the area which the drone was flown corresponds to the lowest altitude which cool-moist convective 


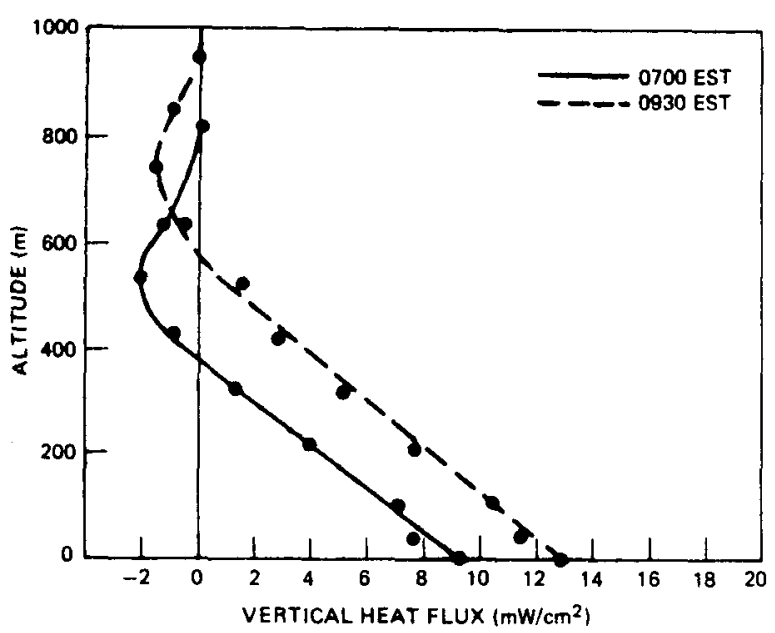

Frg. 10. Heat flux as a function of altitude for two selected times. Note the linear decrease in heat flux with altitude and the slight negative flux at the top of the convective field

elements were observed with the drone. The tentative conclusion drawn from this behavior is that only the cool-moist regions of convective cells are generally visible to the radar. Additional support for this conclusion is contained in Konrad (1970a, b) and Rowland (1972).

Fig. 9 was prepared from plots of temperature vs altitude and shows mean air temperature as a function of time for a selected series of altitudes. The figure further illustrates that the initial effect of the convection upon reaching a given altitude is to cool the air at that altitude. After the initial cooling, the mean air temperature at all altitudes above and including $150 \mathrm{~m}$ increased at the rate of $1.0 \mathrm{C} \mathrm{hr}^{-1}$ between 0650 and 1030. A rate of increase of temperature of $1.0 \mathrm{C} \mathrm{hr}-1$ was observed by Lenchow (1968) on 8 and 10 June 1964 over forested land in northeastern Wisconsin. A rate of increase of temperature of $1.7 \mathrm{C} \mathrm{hr}^{-1}$ was observed by Warner and Telford (1965) on 12 March 1964 in southwestern New South Wales, Australia.

During all soundings, the thickness of the superadiabatic layer was observed to be less than $45 \mathrm{~m}$ and was generally less than $30 \mathrm{~m}$. The average temperature at a height of $1 \mathrm{~m}$, a region well within the superadiabatic layer, increased at a rate of $2.0 \mathrm{C} \mathrm{hr}^{-1}$ between 0650 and 1030. At 1030 the temperature at the $1 \mathrm{~m}$ level stopped increasing and it appears that the rate of increase of temperature at the $150 \mathrm{~m}$ level and above decreased from 1.0 to $0.8 \mathrm{C} \mathrm{hr}^{-1}$. The behavior is coincident with the beginning of the formation of the cumulus. There is, however, no substantial evidence to suggest that the transient formation of such thin and scattered clouds was responsible for this effect, and no completely satisfactory explanation for such behavior has been advanced. It should be noted that time history plots of virtual temperature for a series of selected altitudes also show all the major features of Fig. 9.
Calculations of the vertical heat flux as a function of altitude were made from the rate of change of temperature at a particular altitude for several times between 0700 and 0930 . The method used is described in Lenchow (1968). The heat flux was obtained from

$$
H=\left(\rho c_{p /} / \Delta t\right) \int_{z_{1}}^{z 2} \Delta T d z
$$

where $H$ is the heat flux, $\Delta T$ the change in temperature in the time interval $\Delta t, \rho$ the air density, $c_{p}$ the specific heat of air at a constant pressure, $z_{1}$ the altitude at which the heat flux is being calculated, and $z_{2}$ an altitude above the top of the convection. In such an analysis it is necessary, of course, to assume that there is no heat flux due to horizontal temperature gradients or heat flux from radiation of the moist air.

The results of the calculations at 0700 and 0930 are shown in Fig. 10. Note an approximately linear decrease in flux with height. There is a slight negative heat flux at the top of the convection corresponding to the region where cells are cool and moist with respect to their surroundings. The heat flux increases at all altitudes as time progresses consistent with an increase in the incoming solar radiation expected during this time period. Unfortunately, no heat flux calculations can be made after 0930 since after this time the aircraft soundings did not extend to the top of the convection. A linear lapse rate in heat flux with altitude has been observed by others as summarized by Lenchow (1968). The negative heat flux at the top of the convection is also consistent with the results of Lenchow (1968).

\section{Conclusions}

The drone aircraft and ultra-sensitive Wallops Island radars have proved to be an effective combination for studying atmospheric convection. Large numbers of drone soundings and radar observations at closely spaced time intervals have permitted a detailed description of the behavior of a clear air convective field over a significant portion of its lifetime. Radar pictures and simultaneous drone soundings indicate that radar returns from convective cells are limited to that region of the cell which has overshot its neutral buoyancy level and is cool and moist with respect to its immediate surroundings. Data from other experiments presently being analyzed, including simultaneous radar and meteorological data gathered while the drone circled in individual cells, should lead to an improved description of cells making up the convective field.

Acknowledgments. Appreciation is extended to the many who are responsible for making this experiment possible, among them C. Keller, S. King, J. Morrison and J. Howard, and the crew at the JAFNA radars. The author also wishes to thank M. Hill whose skill 
in building and flying the drone has made this experiment possible. The author is indebted to T. Konrad, who originally conceived the idea of this instrumented drone, for his help in conducting the experiment and for suggestions concerning this paper.

This research was supported by the Air Force Cambridge Research Laboratories and National Aeronautics and Space Administration-Wallops Island.

\section{REFERENCES}

Grant, D. R., 1965: Some aspects of convection as measured from aircraft. Quari. J. Roy. Meleor. Soc., 91, 268-281.

Hardy, K. R., and I. Katz, 1969: Probing the clear atmosphere with high power high resolution radars. Proc. IELE, 57, $468-480$.

- - , and H. Ottersten, 1969 : Radar investigations of convective patterns in the atmosphere. J. Almos. Sci., 26, 666-672.

James, D. G., 1953: Fluctuations of temperature below cumulus clouds. Quart. J. Roy. Meteor. Soc., 79, 425-428.

Jones, R. F., 1954: Five flights through a thunderstorm belt. Quart. J. Roy. Meteor. Soc., 80, 377-387.

Katz, I., 1970: A comparison of remote and in situ measurements in convection. Preprints, 14th Radar Meleor. Conf., Tucson, Amer. Meteor. Soc., 53-55.

Konrad, T. G., 1970a: The dynamics of the convective process in clear air as seen by radar. J. Atmos. Sci., 27, 1138-1147.
--, 1970b: The dynamics of the convective process in clear air as seen by radar. Preprints 14th Radar Meteor. Conf., Tucson, Amer. Meteor. Soc., 57-60.

___ and R. A. Kropfli, 1968: Radar observations of clear air Convection over the sea. Preprints, 13th Radar Meteor. Conf., Montreal, Amer. Meteor. Soc., 262-269.

—, M. L. Hill, J. R. Rowland and J. H. Meyer, 1970: A small, radio-controlled aircraft as a platform for meteorological sensors. Appl. Phys. Lab. Tech. Digest, Nov.-Dec., 11-19.

Lenschow, D. H., 1968: Concurrent airplane and balloon measurements of atmospheric boundary-layer structure over a forest. J. Appl. Meteor., 7, 79-89.

Rowland, J. R., 1971a: Meteorological applications of the bidirectional thermistor mass flow rate sensor. APL/JHU Tech. Memo. TG-1165.

_ 1971b: A method for measuring vertical air velocities with the small instrumented drone aircraft. APL/JHU Memo. MPO $71 \mathrm{U}-29$.

-- -, 1972: Intensive probing of clear air convective fields by radar and instrumented drone aircraft. Preprints, 15th Radar Meteor. Conf., Champaign, Amer. Meteor. Soc., 321-326.

Warner, J., and J. W. Telford, 1963 : Some patterns of convection in the lower atmosphere. J. Atmos. Sci., 20, 313-318.

-- , and —-, 1965: A check of aircraft measurements of vertical heat flux. J. Atmos. Sci., 22, 463-465.

-- , and,- 1967 : Convection below cloud base. I. Almos. Sci., 23, 274-382.

Woodward, B., 1958: The motion in and around isolated thermals. Quart. J. Roy. Meteor. Soc., 85, 144-151. 